\title{
Alcohol consumption, smoking and overweight as a burden for health care services utilization: a cross-sectional study in Estonia
}

\author{
Kaire Vals ${ }^{1,2^{*}}$, Raul-Allan Kiivet ${ }^{1}$ and Mall Leinsalu ${ }^{3,4}$
}

\begin{abstract}
Background: Alcohol consumption, smoking and weight problems are common risk factors for different health problems. We examine how these risk factors are associated with the use of health care services.

Methods: Data for 6500 individuals in the 25-64 age group came from three cross-sectional postal surveys conducted in 2004, 2006, and 2008 in Estonia. The effect of alcohol consumption, smoking and weight problems on the use of primary and specialist care services, hospitalizations and ambulance calls was analysed separately for men and women by using binary logistic regression.

Results: Overweight and/or obesity were strongly related to the use of primary care and out-patient specialist services for both genders, and to hospitalizations and ambulance calls for women. Current smoking was related to ambulance calls for both genders, whereas smoking in the past was related to the use of primary care and specialist services among men and to hospitalizations among women. Beer drinking was negatively associated with all types of health care services and similar association was found between wine drinking and hospitalizations. Wine drinking was positively related to specialist visits. The frequent drinking of strong alcohol led to an increased risk for ambulance calls. Drinking light alcoholic drinks was positively associated with all types of health care services (except ambulance calls) among men and with the use of specialist services among women.

Conclusions: Overweight and smoking had the largest impact on health care utilization in Estonia. Considering the high prevalence of these behavioural risk factors, health policies should prioritize preventive programs that promote healthy lifestyles in order to decrease the disease burden and to reduce health care costs.
\end{abstract}

Keywords: Health care utilization, Smoking, Alcohol, Overweight, Obesity

\section{Background}

Alcohol consumption, smoking and weight problems are common risk factors for different non-communicable diseases such as cardiovascular diseases, type 2 diabetes, pulmonary and orthopaedic diseases and cancers, and also for injuries [1-4]. These risk factors, through their links with consequent health problems incur a large cost for society through premature mortality and extended costs on medical care $[2,5,6]$. Sturm, for example has estimated that as much as $36 \%$ increase in in- and outpatient spending and

\footnotetext{
* Correspondence: kaire.vals@tai.ee

'Department of Public Health, University of Tartu, Ravila 19, Tartu 50411, Estonia

${ }^{2}$ Infectious Diseases and Drug Monitoring Department, National Institute for Health Development, Tallinn, Estonia

Full list of author information is available at the end of the article
}

$77 \%$ increase in medications can be attributed to weight problems, and $21 \%$ and $28 \%$ respectively to smoking [5]. Haapanen-Niemi found that male smokers had up to $70 \%$ more hospital days due to health conditions compared to those who had never smoked [7]. Problem drinking has mainly been related to the extended use of acute medical services $[8,9]$.

In Estonia about $33 \%$ of the total disease burden is attributable to cardiovascular diseases, $20 \%$ to cancers, and $12 \%$ to external causes of death such as traffic accidents, falls, suicides and homicides [10], all at least partly affected by unhealthy behaviours. Smoking, alcohol consumption, overweight and obesity are highly prevalent among the general population in Estonia [11]. Since the 1990s, an increase has been reported for alcohol consumption and

\section{Biomed Central}

(c) 2013 Vals et al.; licensee BioMed Central Ltd. This is an Open Access article distributed under the terms of the Creative Commons Attribution License (http://creativecommons.org/licenses/by/2.0), which permits unrestricted use, distribution, and reproduction in any medium, provided the original work is properly cited. 
obesity (the latter only among men) [12,13]. The increasing prevalence of obesity follows similar trends in other countries $[14,15]$. At the same time the prevalence of daily smoking has decreased in recent years [11], with a steeper decline observed in men as predicted by the progression of the tobacco epidemic [16].

The Estonian health care system is funded on a solidarity basis. Medical expenditures incurred by children, retired persons and employees are paid by the Estonian Health Insurance Fund (EHIF) which is financed through a social security tax (34.4\% of gross earnings). About $95 \%$ of the Estonian population is covered by the EHIF [17]. In accordance with overall economic growth, the total per capita costs of the health sector doubled between 2004 and 2008. The share of health expenditures as a percentage of GDP increased from $5.2 \%$ in 2004 to $6.1 \%$ in 2008 with up to a $10 \%$ increase occurring in the number of contacts with health care services over this period [18]. Previous studies in Estonia have demonstrated a strong effect of socioeconomic factors on the use of health care services $[19,20]$ with more deprived groups being less likely to use primary and specialist care or to visit the dentist when compared to those with higher social status. These studies, however, did not look at the impact of unhealthy behaviours that could underlie the observed differences. Such behaviours may have an independent effect on health care utilization, as shown for obesity in a recent study by Tekkel et al [13], and in this way, impose a heavy burden on health care in society.

The aim of this study is to analyse the association between alcohol consumption, smoking and weight problems with the use of health care services among the adult population in Estonia. This knowledge will improve our understanding of the underlying causes of health care utilization and thus help the health authorities to better ground their strategies, which is essential for the more effective use of health care resources.

\section{Methods}

Data

The data were drawn from the Health Behaviour Survey of the Estonian Adult Population, a nationally representative cross-sectional postal survey. The survey is part of the collaborative Finbalt Health Monitoring project described in detail elsewhere [21]. In Estonia, the survey has been conducted in every second year since 1990 and the data are freely available upon request. A simple random sample of the Estonian population aged 16-64 years has been drawn from the population register for each survey. The questionnaires were compiled in both Estonian and Russian and were for the most part mailed in April and May. After two weeks a first reminder was sent to those who had not responded, and a second reminder was sent after another two weeks. We combined data from three surveys conducted in 2004, 2006 and 2008 in order to increase statistical power. The adjusted response rate was $62 \%$ in $2004(\mathrm{n}=3074), 57 \%$ in $2006(\mathrm{n}=2867)$ and $62 \%$ in $2008(\mathrm{n}=3004)[11,22,23]$. We excluded respondents younger than 25 years of age as this group might not yet have achieved their highest educational level which could result in their socioeconomic status being underestimated compared to older respondents. All respondents who had missing values for any of the study variables were additionally excluded from the final sample which consisted of 6500 individuals in the 25-64 age group.

\section{Outcome variables}

Utilization of health care was studied for four types of services. The first indicator measures the proportion of respondents who had visited a general practitioner (GP) over the past 12 months. This variable covers visits at the primary care level. The second variable covers visits to out-patient specialists over the past 12 months, excluding dentists. The third indicator measures the proportion of respondents who had been hospitalized (for any reason) during the 12 months preceding the survey. The fourth indicator measures the proportion of respondents who had made an ambulance call over the past 12 months.

\section{Independent variables}

The association with health care utilization was assessed for alcohol consumption, smoking and weight problems. Alcohol consumption was measured by the average frequency of drinking in the past 12 months separately for strong alcohol, wine, beer, and light alcoholic drinks. The answer categories were divided into three groups for each type of beverage: has not drunk (reference group), has drunk a few times a month or less (combining the categories 'a few times a year' and 'a few times a month'), and has drunk at least a few times a week (combining the categories 'a few times a week' and 'every day'). For smoking the answer categories were combined into three groups: those who had never smoked (reference group), those who had smoked in the past, and current smokers. Occasional smokers were classified as current smokers as we were not able to classify them as never smokers or ex-smokers. Weight problems were assessed on the basis of body mass index calculated from self-reported height and weight $\left[\mathrm{BMI}=\right.$ weight $(\mathrm{kg}) /$ height $\left.(\mathrm{m})^{2}\right]$. Respondents were divided into four categories: underweight $(\mathrm{BMI}<18.50)$, normal weight (18.50-24.99), overweight (25.00-29.99), and obese $(\geq 30.00)$. The normal weight category was used as a reference group.

\section{Control variables}

In order to control for the possible effect of confounding by socioeconomic variables, we adjusted our analysis for education (categorized as university, upper secondary and 
lower secondary education), average household income (divided into high, mid and low income groups) and selfdefined ethnic identity (Estonian, Russian and other). These indicators are known from previous studies to be related to both health care use and to health behaviours $[12,13,20,24]$. We additionally adjusted models for age and for study year, the latter to control for any period effect.

\section{Statistical analysis}

The data were analysed separately for men and women. Relative differences were evaluated by means of binary logistic regression using the STATA 12 statistical package. The effect of each independent variable was measured in two models. The first model included only age (in 5-year age groups) and the risk factor of interest. The second model was mutually adjusted for age, alcohol consumption (all four measures), smoking and BMI, as well as for education, income, ethnicity and study year. The differences between the two models were small and we therefore show the results only for the multivariate models. The results are presented as odds ratios (ORs) with $95 \%$ confidence intervals (CIs).

\section{Ethics committee approval}

The surveys have been approved by the Tallinn Medical Research Ethics Committee. The data used in the current study are anonymous.

\section{Results}

The sample characteristics are presented in Table 1. Alcohol consumption, smoking and weight problems were all highly prevalent among respondents. Nearly $16 \%$ of men drank strong alcohol and $42 \%$ drank beer at least a few times a week. Almost $8 \%$ of women drank wine with the same frequency. $78 \%$ of men and $48 \%$ of women had been smokers at some period in their life and $59 \%$ of men and $48 \%$ of women were overweight or obese. Large gender differences were present for alcohol consumption and smoking, whereas these differences were modest for obesity. Women tended to use primary health care and outpatient specialist services more often than men.

Table 2 presents the results for the use of primary care and out-patient specialist services. The consumption of strong alcohol or wine was not related to the use of primary care services in either men and women. Drinking beer or light alcoholic drinks was not related to the use of primary care services among women, however, men who drank beer at least a few times a week were less likely to visit a general practitioner (GP), and men who drank light alcoholic drinks a few times a week were more likely $(\mathrm{OR}=1.57)$ to visit a GP compared to those who did not drink these beverages. Smoking in the past was related to the use of primary care services among men but not women. Both overweight and obesity were positively related to the use of primary care services in men and women. The odds of visiting a GP were almost $80 \%$ higher for obese women and $32 \%$ higher for obese men than for those who were a normal weight.

Drinking strong alcohol was also not related to the use of outpatient specialist care services on a statistically significant level, though a somewhat $(\mathrm{OR}=1.34)$ elevated risk was observed for men who drank strong alcohol at least a few times a week. Drinking wine or light alcoholic drinks a few times a month or less was associated with a $21-24 \%$ increase in the odds of visiting a specialist for both genders, whereas beer drinking was negatively associated with specialist care use. While male ex-smokers used specialist care more often $(\mathrm{OR}=1.26)$ than never smokers, current smoking had a negative association (among women on a statistically significant level) with specialist care use. Both obese men and women had $28 \%$ higher odds of visiting a specialist compared to respondents whose weight was normal.

Table 3 combines the results for hospitalizations and ambulance calls. Except for drinking light alcoholic drinks at least a few times a week ( $\mathrm{OR}=1.81$, men only), alcohol consumption was not related with a higher risk for hospitalizations. In contrast, wine drinking was negatively associated with hospitalizations among both men and women. Women, who smoked in the past had nearly $50 \%$ higher odds for hospitalizations compared to never smokers, but no association was observed with current smoking for either genders. Obese women had more than 50\% higher odds for hospitalizations, but no association was observed among men who were either overweight or obese.

Drinking strong alcohol at least a few times a week was associated with a two times $(\mathrm{OR}=2.10)$ higher risk for ambulance calls among women compared to those women who had not drunk strong alcohol. Though slightly elevated $(\mathrm{OR}=1.35)$, this association was not statistically significant for men. Frequent consumption of wine or beer showed a negative association (statistically not significant) with ambulance calls. Both men and women who were current smokers had higher odds for ambulance calls compared to never smokers (respective odds ratios 1.63 and 1.38). Women who had smoked in the past also had an elevated risk $(\mathrm{OR}=1.38)$ but the association was not statistically significant. Both obesity and underweight $(\mathrm{OR}=1.45$; $\mathrm{OR}=2.51$ ) increased the risk for ambulance calls among women, whereas a much higher risk in men who were underweight was not statistically significant.

\section{Discussion}

Our study showed that alcohol consumption, smoking and weight problems were associated with the health care utilization, though the results varied by gender and type of services. Overweight and/or obesity were strongly related with the use of primary care and out-patient specialist services for both genders, and with hospitalizations and 
Table 1 Characteristics of the study population

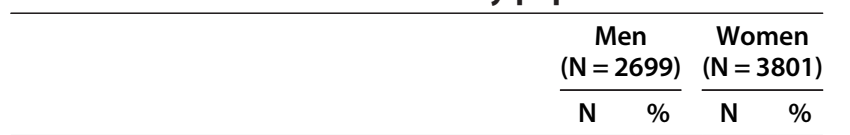

Strong alcohol consumption in past12 months

Has not drunk

A few times a month or less

$399 \quad 14.8 \quad 1345 \quad 35.4$

At least a few times a week

Wine consumption in past 12 months

Has not drunk

A few times a month or less

At least a few times a week

Beer consumption in past 12 months

Has not drunk

A few times a month or less

At least a few times a week

Light alcoholic drinks consumption in past 12 months

Has not drunk

A few times a month or less

At least a few times a week

Smoking

Has never smoked

Has smoked in the past

Current smoker

$\mathrm{BMI}$

Normal weight (18.5-24.99)

Underweight $(<18.50)$

Overweight (25-29.99)

Obesity $(\geq 30)$

General practitioner

No

Yes

Specialized care

No

Yes

Hospitalization

No

Yes

Ambulance calls

No

Yes

Education

University

Upper secondary

Lower secondary

Household income
Table 1 Characteristics of the study population

(Continued)

\begin{tabular}{lcccc}
\hline Higher 1/3 & 873 & 32.4 & 977 & 25.7 \\
Mid 1/3 & 1005 & 37.2 & 1515 & 40.0 \\
Lower 1/3 & 821 & 30.4 & 1309 & 34.3 \\
Ethnicity & & & & \\
Estonians & 1906 & 70.6 & 2619 & 68.9 \\
Russians & 644 & 23.9 & 960 & 25.3 \\
Other & 149 & 5.5 & 222 & 5.8 \\
Age group & & & & \\
$25-29$ & 333 & 12.3 & 422 & 11.1 \\
$30-34$ & 355 & 13.2 & 485 & 12.8 \\
$35-39$ & 312 & 11.6 & 450 & 11.8 \\
$40-44$ & 354 & 13.1 & 455 & 12.0 \\
$45-49$ & 338 & 12.5 & 514 & 13.5 \\
$50-54$ & 360 & 13.3 & 508 & 13.4 \\
$55-59$ & 314 & 11.6 & 495 & 13.0 \\
$60-64$ & 333 & 12.4 & 472 & 12.4 \\
\hline
\end{tabular}

ambulance calls for women. Current smoking was strongly related to ambulance calls for both genders, whereas smoking in the past was related to the use of primary care and specialist services among men and to hospitalizations among women. Beer drinking was negatively associated with all types of health care services use and a similar association was found between wine drinking and hospitalizations. At the same time wine drinking was positively related to specialist visits. The frequent drinking of strong alcohol led to an increased risk for ambulance calls. Drinking light alcoholic drinks was positively associated with all types of health care services (except ambulance calls) among men and with the use of specialist services among women.

This study has several limitations which should be noted before the discussion of the main findings. First, the survey response rate varied between 57\% in 2006 and 62\% in 2004 and 2008. In Estonia, a relatively large part of the survey non-response is related to an inability to reach respondents at a given address [22,23], which to some extent reflects the poorly recorded out-migration in recent years. Nonresponse tended to be slightly higher among men and in the younger age groups across all surveys covered in this study. The results are biased only if non-respondents systematically differ from respondents. Respondents usually tend to have better health and healthier lifestyles compared to non-respondents [25] but there is no particular reason to believe that non-respondents who engage in unhealthy behaviours or who are in worse health use health services differently than respondents with the same characteristics, though some underestimation of the associations is possible. Previous research has also shown that non-response is unlikely to affect the results in terms of the studied 
Table 2 The association* of alcohol consumption, smoking and weight problems with the use of primary care and out-patient specialist services

\begin{tabular}{|c|c|c|c|c|}
\hline & \multicolumn{2}{|c|}{ Use of primary care services } & \multicolumn{2}{|c|}{ Use of out-patient specialist services } \\
\hline & Men & Women & Men & Women \\
\hline & OR $(95 \% \mathrm{Cl})$ & OR $(95 \% \mathrm{Cl})$ & OR $(95 \% \mathrm{Cl})$ & OR $(95 \% \mathrm{Cl})$ \\
\hline \multicolumn{5}{|c|}{ Strong alcohol consumption in past 12 months } \\
\hline Has not drunk & 1 & 1 & 1 & 1 \\
\hline A few times a month or less & $1.02(0.80-1.32)$ & $1.13(0.96-1.33)$ & $1.17(0.91-1.51)$ & $1.09(0.94-1.26)$ \\
\hline At least a few times a week & $0.85(0.63-1.16)$ & $0.71(0.45-1.12)$ & $1.34(0.98-1.83)$ & $1.11(0.73-1.72)$ \\
\hline \multicolumn{5}{|c|}{ Wine consumption in past 12 months } \\
\hline Has not drunk & 1 & 1 & 1 & 1 \\
\hline A few times a month or less & $0.97(0.80-1.18)$ & $0.93(0.77-1.12)$ & $1.21(1.00-1.48)$ & $1.24(1.05-1.46)$ \\
\hline At least a few times a week & $1.02(0.72-1.43)$ & $1.04(0.75-1.44)$ & $1.23(0.87-1.72)$ & $1.05(0.79-1.41)$ \\
\hline \multicolumn{5}{|c|}{ Beer consumption in past 12 months } \\
\hline Has not drunk & 1 & 1 & 1 & 1 \\
\hline A few times a month or less & $0.88(0.69-1.12)$ & $0.86(0.73-1.02)$ & $0.86(0.68-1.09)$ & $0.96(0.82-1.11)$ \\
\hline At least a few times a week & $0.71(0.56-0.90)$ & $0.83(0.62-1.12)$ & $0.65(0.52-0.82)$ & $0.76(0.58-0.99)$ \\
\hline \multicolumn{5}{|c|}{ Light alcoholic drinks consumption in past 12 months } \\
\hline Has not drunk & 1 & 1 & 1 & 1 \\
\hline A few times a month or less & $1.21(0.98-1.48)$ & $1.01(0.86-1.20)$ & $1.23(1.00-1.51)$ & $1.24(1.07-1.44)$ \\
\hline At least a few times a week & $1.57(1.08-2.29)$ & $1.28(0.88-1.86)$ & $1.12(0.78-1.60)$ & $1.11(0.80-1.53)$ \\
\hline \multicolumn{5}{|l|}{ Smoking } \\
\hline Has never smoked & 1 & 1 & 1 & 1 \\
\hline Has smoked in the past & $1.43(1.13-1.81)$ & $0.96(0.79-1.16)$ & $1.26(1.01-1.58)$ & $1.03(0.87-1.23)$ \\
\hline Current smoker & $1.12(0.90-1.39)$ & $0.99(0.82-1.19)$ & $0.81(0.65-1.01)$ & $0.84(0.71-0.99)$ \\
\hline \multicolumn{5}{|l|}{ BMI } \\
\hline Normal weight (18.5-24.99) & 1 & 1 & 1 & 1 \\
\hline Underweight (<18.50) & $1.27(0.47-3.45)$ & $1.06(0.67-1.68)$ & $1.52(0.59-3.92)$ & $1.20(0.78-1.85)$ \\
\hline Overweight (25-29.99) & $1.21(1.01-1.45)$ & $1.19(1.00-1.43)$ & $1.09(0.91-1.31)$ & $1.00(0.85-1.17)$ \\
\hline Obesity ( $\geq 30)$ & $1.32(1.04-1.68)$ & $1.76(1.40-2.21)$ & $1.28(1.01-1.61)$ & $1.28(1.06-1.55)$ \\
\hline
\end{tabular}

Models are mutually adjusted for age, alcohol consumption (all four variables), smoking, BMI, education, income, ethnicity and study year. 
Table 3 The association ${ }^{*}$ of alcohol consumption, smoking and weight problems with hospitalizations and ambulance calls

\begin{tabular}{|c|c|c|c|c|}
\hline & \multicolumn{2}{|c|}{ Hospitalizations } & \multicolumn{2}{|c|}{ Ambulance calls } \\
\hline & Men & Women & Men & Women \\
\hline & OR $(95 a \% \mathrm{Cl})$ & OR $(95 \% \mathrm{Cl})$ & OR $(95 \% \mathrm{Cl})$ & OR $(95 \% \mathrm{Cl})$ \\
\hline \multicolumn{5}{|c|}{ Strong alcohol consumption in past 12 months } \\
\hline Has not drunk & 1 & 1 & 1 & 1 \\
\hline A few times a month or less & $0.84(0.58-1.20)$ & $0.81(0.65-1.02)$ & $1.06(0.68-1.68)$ & $1.00(0.75-1.33)$ \\
\hline At least a few times a week & $1.19(0.76-1.84)$ & $0.86(0.43-1.74)$ & $1.35(0.79-2.31)$ & $2.10(1.05-4.22)$ \\
\hline \multicolumn{5}{|c|}{ Wine consumption in past 12 months } \\
\hline Has not drunk & 1 & 1 & 1 & 1 \\
\hline A few times a month or less & $0.87(0.64-1.17)$ & $0.74(0.58-0.94)$ & $0.70(0.48-1.02)$ & $0.88(0.65-1.20)$ \\
\hline At least a few times a week & $0.42(0.21-0.84)$ & $0.54(0.32-0.92)$ & $0.74(0.37-1.51)$ & $0.61(0.31-1.19)$ \\
\hline \multicolumn{5}{|c|}{ Beer consumption in past 12 months } \\
\hline Has not drunk & 1 & 1 & 1 & 1 \\
\hline A few times a month or less & $1.05(0.74-1.49)$ & $0.94(0.73-1.19)$ & $0.88(0.57-1.34)$ & $0.95(0.70-1.29)$ \\
\hline At least a few times a week & $0.76(0.53-1.07)$ & $0.79(0.50-1.27)$ & $0.66(0.43-1.00)$ & $0.87(0.50-1.52)$ \\
\hline \multicolumn{5}{|c|}{ Light alcoholic drinks consumption in past 12 months } \\
\hline Has not drunk & 1 & 1 & 1 & 1 \\
\hline A few times a month or less & $1.21(0.87-1.70)$ & $0.87(0.68-1.10)$ & $1.27(0.84-1.92)$ & $1.06(0.78-1.43)$ \\
\hline At least a few times a week & $1.81(1.08-3.03)$ & $0.90(0.51-1.57)$ & $1.05(0.51-2.17)$ & $1.41(0.76-2.61)$ \\
\hline \multicolumn{5}{|l|}{ Smoking } \\
\hline Has never smoked & 1 & 1 & 1 & 1 \\
\hline Has smoked in the past & $0.94(0.65-1.35)$ & $1.47(1.13-1.90)$ & $1.16(0.70-1.94)$ & $1.38(0.98-1.94)$ \\
\hline Current smoker & $0.95(0.68-1.34)$ & $1.05(0.80-1.36)$ & $1.63(1.03-2.57)$ & $1.38(1.00-1.90)$ \\
\hline \multicolumn{5}{|l|}{ BMI } \\
\hline Normal weight (18.5-24.99) & 1 & 1 & 1 & 1 \\
\hline Underweight (<18.50) & $1.88(0.59-5.96)$ & $1.54(0.85-2.81)$ & $1.96(0.54-7.17)$ & $2.51(1.30-4.88)$ \\
\hline Overweight (25-29.99) & $0.75(0.56-1.00)$ & $1.17(0.91-1.52)$ & $0.86(0.61-1.22)$ & $1.13(0.81-1.58)$ \\
\hline Obesity $(\geq 30)$ & $0.95(0.67-1.36)$ & $1.54(1.16-2.05)$ & $0.79(0.50-1.26)$ & $1.45(1.01-2.07)$ \\
\hline
\end{tabular}

Models are mutually adjusted for age, alcohol consumption (all four variables), smoking, BMI, education, income, ethnicity and study year. 
associations [25]. Second, the general propensity of respondents to give socially desirable answers, may have led to the underreporting of weight (and consequently the BMI), smoking or alcohol consumption [26-28]. In that case, some underestimation of the associations is possible. Similarly, by classifying occasional smokers as current smokers we may have somewhat underestimated the association between current smoking and the use of health care services. Third, we excluded all cases with missing values in our analyses. However, comparing the results from the bivariate analysis (data not shown) revealed no major differences between the samples with or without the exclusion of cases with missing values. In conclusion, although we cannot exclude the possibility of some underestimation of the associations, we believe that our results generally are not biased in any major way.

The detrimental effect of alcohol on numerous causes of death has increasingly been reported, particularly in relation to Eastern Europe [29]. The harmful effects of alcohol, both chronic and acute, are likely to annul any positive effect of alcohol on health [4]. The estimated social costs of alcohol misuse (1.6\% of GDP), including the costs to the health care system are high in Estonia compared to many other countries [30]. Previous findings of the effect of alcohol consumption on health care services utilization have not been consistent. Most studies have reported the negative association between alcohol consumption and the use of out-patient health care services [8,31,32]. Similar to these findings, the frequent consumption of alcohol has also been related to better self-rated health [33]. For inpatient services some studies have reported an inverse relationship [32,34] whereas some studies have found increased usage among problem drinkers $[8,9,31]$. The latter has mostly been related to the extended use of acute medical services $[8,9,35]$ or to certain health problems like injuries and accidents [7]. Life-time abstainers have consistently been found to use health services more often than moderate drinkers [31,36], which suggests that the association may have a U-shaped form. To a large extent our results accord with previous studies i.e. alcohol consumption is largely associated with a diminished use of both in- and out-patient health care services, though frequent consumption of strong alcohol was related to ambulance calls and wine consumption was related to the use of out-patient specialist care. The inverse association between drinking and health care use may be partly related to the fact that persons with the most serious drinking problems are not participating in the surveys. They may also be more careless about their health and less willing to use health care services [7], especially general practitioners. Missed care, however, may lead to more serious and often fatal health outcomes which in turn would lay an even higher economic burden on society. This could also explain the different pattern we found for ambulance calls. In Estonia, like in other countries of the former Soviet Union, alcohol consumption is considered as a normative male behaviour [37]. Non-drinking in such circumstances may be related to poor health status and more frequent use of health care, which may partly explain the inverse associations with health care use in our study. It is also possible that the group of non-drinkers in our study included ex-drinkers who had stopped drinking for health reasons. The strong positive association between the consumption of light alcoholic drinks and the use of in-and out-patient health care services, especially among men, is interesting but needs more research. Not being a typical male drink, light alcohol may be used as a replacement for strong alcohol after the occurrence of health problems or it may be related to different health risks affecting the use of health services.

Smoking is one of the most serious threats for several health conditions [38]. In 2005, 16\% of all deaths in adults over 30 years in the WHO European Region were due to tobacco [39]. Tobacco is responsible for $10 \%$ of all deaths from cardiovascular diseases, $22 \%$ of all cancer deaths, and $36 \%$ of all deaths from diseases of the respiratory system [39]. This implies that health care costs for smokers are higher than for non-smokers [2]. It has been shown that the increased medical costs among smokers were mainly attributable to the increased use of inpatient medical care [40]. Several other studies have shown that current smoking or smoking in the past greatly increases the number of hospitalizations and days spent in hospital $[7,9,32,41,42]$. This is different for out-patient health care where it has been found that current smokers use services less or similarly to never-smokers [40-43]. Jorm additionally reported that current smokers were less likely to use primary care services where out-of-pocket payment was necessary, and less likely to use some preventive services [43]. Former smokers have been found to use out-patient services more than never-smokers [32,41]. In line with these results, current smoking also showed a strong and positive association with ambulance calls for both genders in our study, although hospitalizations were related to former smoking only among women. Considering the high prevalence of smoking and the high burden of smoking related diseases in Estonia [39], it is surprising that neither current or past smoking were related to hospitalizations among men. In contrast to many other studies $[7,40]$, our study used a cross-sectional design which implies that only survivors were represented among past hospital users. Higher lethality among smokers compared to never-smokers could possibly explain why we did not find any differences in hospitalizations between smokers, ex-smokers and never smokers. On the other hand, the occurrence of health problems may have led to smokers quitting [44], thus explaining the positive association with primary and specialized care use by former male smokers. 
Current smoking was not related to the use of primary care, although women who were current smokers used specialist care less often than never-smokers. Similar to alcohol drinking, tobacco smoking has been related to enjoyment and stress relief [45] which may explain why current smoking is not always associated with poor subjective perceptions of health [33]. Smokers tend to see the risks of smoking as being lower which may lead to the denial of health problems and to delays in seeking care or preventive services $[43,46]$.

The increasing prevalence of overweight and obesity has become one of the most serious health risks in the modern world $[8,14,15]$. Overweight and obesity are mainly related to cardiovascular diseases such as coronary heart disease, and type 2 diabetes but also to orthopaedic problems and cancers $[6,14,47]$. Previous studies have demonstrated a strong association between overweight and obesity and the use of primary and specialized care, hospitalizations and the use of emergency care $[6,48]$, thus imposing large and increasing health care costs on society $[5,49,50]$. In our study, the strongest associations with health care utilization were found for weight problems. Differently from alcohol consumption and smoking, obesity and/or overweight showed a positive and statistically significant association with all types of health care services, though some genderbased exceptions were observed. The stronger association between obesity and the use of health care services among women (except for specialist care) might be explained by the fact that obesity has a genuinely greater impact on women's health [51]. On the other hand, as the weight categories are defined by using the same cut-off points for both genders, the greater muscle content of men in the same weight categories may be another reason why overweight and obesity were not as strongly related to health care use among men. Obesity has been related to lower levels of taking Pap tests among women [52], which may partly explain the more equal gender pattern of using specialist care in our study. Although only a relatively small proportion of respondents were underweight, this condition was nevertheless strongly related to ambulance calls among women. Underweight may be a risk factor for health in its own right [47], however, weight loss may also happen as a result of disease. Compared to alcohol and tobacco consumption, obesity may be more related to health conditions that are causing subjective discomfort, thus resulting in more visits to general practitioners.

\section{Conclusions}

Smoking and weight problems impose a significant burden for health care utilization independently from other risk factors. This study points to the necessity of evidence based interventions to reduce the prevalence of unhealthy behaviours and related health problems. For example, the implementation of smoke-free legislation in England has been associated with a reduction in the number of myocardial infarction emergency admissions [53]. Taxation and access control have also proved to be effective tools in reducing tobacco and alcohol consumption among the population $[38,54]$, and other fiscal policies might be similarly effective in terms of weight control [55]. Promoting regular physical exercise and a healthy diet with a focus on work or school settings could be other intervention strategies to reduce the obesity epidemic in the general population [15]. The alcohol-related burden on health care services needs further clarification, possibly by using longitudinal study designs.

\section{Competing interests}

The authors declare that they have no competing interest.

\section{Authors' contributions}

$\mathrm{KV}$ and $\mathrm{ML}$ conceived and designed the study. KV conducted the data analyses and drafted the manuscript. ML discussed the core ideas and contributed intellectually to all versions of the manuscript. RAK commented on the earlier drafts. All authors read and approved the final manuscript.

\section{Acknowledgements}

We thank Dr Mare Tekkel from the Department of Epidemiology and Biostatistics, the National Institute for Health Development, Estonia, for kindly providing us with the data for this study. ML's work has been supported by the Swedish Foundation for Baltic and East European Studies (grant A052-10) and by the Estonian Research Council (grant IUT5-1).

\section{Author details}

${ }^{1}$ Department of Public Health, University of Tartu, Ravila 19, Tartu 50411, Estonia. ${ }^{2}$ Infectious Diseases and Drug Monitoring Department, National Institute for Health Development, Tallinn, Estonia. ${ }^{3}$ Stockholm Centre on Health of Societies in Transition, Södertörn University, Stockholm, Sweden. ${ }^{4}$ Department of Epidemiology and Biostatistics, National Institute for Health Development, Tallinn, Estonia.

Received: 25 January 2013 Accepted: 20 August 2013

Published: 23 August 2013

\section{References}

1. Gmel G, Givel J-C, Yersin B, Daeppen J-B: Injury and repeated injury - what is the link with acute consumption, binge drinking and chronic heavy alcohol use? Swiss Med WKLY 2007, 137:642-648.

2. Baliunas D, Patra J, Rehm J, Popova S, Taylor B: Smoking-attributable morbidity: acute care hospital diagnoses and days of treatment in Canada, 2002. BMC Publ Health 2007, 7:247-254.

3. Lenz M, Richter T, Mühlhauser I: The morbidity and mortality associated with overweight and obesity in adulthood. Dtsch Arztebl Int 2009, 106:641-648.

4. Rehm J, Mathers C, Popova S, Thavorncharoensap M, Teerawattananon Y, Patra J: Global burden of disease and injury and economic cost attributable to alcohol use and alcohol-use disorders. Lancet 2009, 373:2223-2233.

5. Sturm R: The effects of obesity, smoking, and drinking on medical problems and costs. Obesity outranks both smoking and drinking in its deleterious effects on health and health costs. Health Aff (Millwood) 2002, 21:245-253.

6. Bertakis KD, Azari R: Obesity and the use of health care service. Obes Res 2005, 13:372-379.

7. Haapanen-Niemi N, Miilunpalo S, Vuori I, Pasanen M, Oja P: The impact of smoking, alcohol consumption, and physical activity on use of hospital services. Am J Publ Health 1999, 89:691-698.

8. Cryer PC, Jenkins LM, Cook AC, Ditchburn JS, Harris CK, Davis AR, Peters TJ: The use of acute and preventative medical services by a general population: relationship to alcohol consumption. Addiction 1999 , 94:1523-1532.

9. Bertakis KD, Azari R: The influence of obesity, alcohol abuse, and smoking on utilization of health care services. Fam Med 2006, 38:427-434. 
10. Tartu Ülikooli tervishoiu instituut and Eesti Sotsiaalministeerium: Haiguskoormuse tỗtu kaotatud eluaastad Eestis: seosed riskifaktoritega ja riskide vähendamise kulutõhusus. Tartu: Tartu Ülikool: The burden of disease in Estonia: associations with riskfactors and cost-effectiveness of risk interventions; 2004.

11. Tekkel M, Veideman T, Rahu M: Eesti täiskasvanud elanikkonna tervisekäitumise uuring, 2008, Health behavior among Estonian adult population. Tallinn: Tervise Arengu Instituut; 2009.

12. Pärna K, Rahu K, Helakorpi S, Tekkel M: Alcohol consumption in Estonia and Finland: Finbalt survey 1994-2006. BMC Publ Health 2010, 10:261.

13. Tekkel M, Veideman T, Rahu M: Changes over fourteen years in adult obesity in Estonia: socioeconomic status and use of outpatient health care services. Cent Eur J Publ Health 2010, 18:186-191.

14. Knai C, Suhrcke M, Lobstein T: Obesity in Eastern Europe: an overview of its health and economic implications. Econ Hum Biol 2007, 5:392-408.

15. Heeb J-L: Changes in the prevalence of overweight and obesity: some evidence from the Swiss Health Surveys $1992 / 93$ and 2002. Eur J Publ Health 2009, 21:407-413.

16. Lopez AD, Collishaw NE, Piha T: A descriptive model of the cigarette epidemic in developed countries. Tob Control 1994, 3:242-247.

17. Koppel A, Kahur K, Habicht T, Saar P, Habicht J, van Ginneken E: Estonia: Health system review. Health Syst Transit 2008, 10:1-230.

18. National Institute for Health Development: Health statistics and health research database. Available at: [http://pxweb.tai.ee/esf/pxweb2008/Dialog/ statfile1.asp] Accessed 27 May.

19. Habicht J, Kunst AE: Social inequalities in health care services utilization after eight years of health care reforms: a cross-sectional study of Estonia, 1999. Soc Sci Med 2005, 60:777-787.

20. Habicht J, Kiivet R-A, Habicht T, Kunst AE: Social inequalities in the use of health care services after 8 years of health care reforms - a comparative study of the Baltic countries. Int J Publ Health 2009, 54:250-259.

21. Prättälä R, Helasoja V, Finbalt-group: Finbalt Health Monitor. Feasibility of a collaborative system for monitoring health behaviour in Finland and the Baltic countries. Report No. B21/1999. Helsinki: Publications of the National Public Health Institute; 1999.

22. Tervise Arengu Instituut: Eesti täiskasvanud elanikkonna tervisekäitumise uuring, 2004, Health behavior among Estonian adult population, 2004 Tallinn: Tervise Arengu Instituut; 2005

23. Tekkel M, Veideman T, Rahu M: Eesti täiskasvanud elanikkonna tervisekäitumise uuring, 2006, Health behavior among Estonian adult population, 2006. Tallinn: Tervise Arengu Instituut; 2007.

24. Leinsalu $M$, Tekkel M, Kunst AE: Social determinants of ever initiating smoking differ from those of quitting: a cross-sectional study in Estonia. Eur J Publ Health 2007, 17:572-578.

25. Van Loon AJM, Tijhuis M, Picavet HSJ, Surtees PG, Ormel J: Survey nonresponse in the Netherlands: Effects on prevalence estimates and associations. Ann Epidemiol 2003, 13:105-110.

26. Stommel M, Schoenborn CA: Accuracy and usefulness of BMI measures based on self-reported weight and height: findings from the NHANES \& NHIS 2001-2006. BMC Publ Health 2009, 9:421.

27. Connor Gorber S, Schofield-Hurwitz S, Hardt J, Levasseur G, Tremblay M: The accuracy of self-reported smoking: a systematic review of the relationship between self-reported and cotinine-assessed smoking status. Nicotine Tob Res 2009, 11:12-24.

28. Poikolainen $\mathrm{K}$ : Underestimation of recalled alcohol intake in relation to actual consumption. Br J Addict 1985, 80:215-216.

29. Rehm J, Sulkowska U, Mańczuk M, Boffetta P, Powles J, Popova S, Zatoński W: Alcohol accounts for a high proportion of premature mortality in central and eastern Europe. Int J Epidemiol 2007, 36:458-467.

30. Saar I: The social costs of alcohol misuse in Estonia. Eur Addict Res 2009, 15:56-62.

31. Anzai Y, Kuriyama S, Nishino Y, Takahashi K, Ohkubo T, Ohmori K, Tsubono $Y$, Tsuji I: Impact of alcohol consumption upon medical care utilization and costs in men: 4-year observation of National Health Insurance beneficiaries in Japan. Addiction 2005, 100:19-27.

32. Rodríguez Artalejo F, de Andrés MB, Guallar-Castillón P, Puente Mendizabal MT, González Enríquez J, del Rey CJ: The association of tobacco and alcohol consumption with the use of health care services in Spain. Prev Med 2000, 31:554-561.

33. Kasmel A, Helasoja V, Lipand A, Prättälä R, Klumbiene J, Pudule I: Association between health behaviour and self-reported health in Estonia, Finland, Latvia and Lithuania. Eur J Publ Health 2004, 14:32-36.
34. Baumeister SE, Meyer C, Carreon D, Freyer J, Rumpf HJ, Hapke U, John U, Alte D: Alcohol consumption and health-services utilization in Germany. J Stud Alcohol 2006, 67:429-435.

35. Cherpitel $\mathrm{CJ}$ : Emergency room and primary care services utilization and associated alcohol and drug use in the United States general population. Alcohol Alcohol 1999, 34:581-589.

36. Baumeister SE, Schumann A, Nakazono T, Alte D, Friedrich N, John U, Völzke H: Alcohol consumption and out-patient services utilization by abstainers and drinkers. Addiction 2006, 101:1285-1291.

37. Cockerham WC, Hinote BP, Abbott P: Psychological distress, gender, and health lifestyles in Belarus, Kazakhstan, Russia, and Ukraine. Soc Sci Med 2006, 63:2381-2394.

38. Jha P, Chaloupka FJ, Corrao M, Jacob B: Reducing the burden of smoking world-wide: effectiveness of interventions and their coverage. Drug Alcohol Rev 2006, 25:597-609.

39. WHO: WHO global report: mortality attributable to tobacco. Geneva: WHO; 2012. Available at: http://whqlibdoc.who.int/publications/2012/ 9789241564434_eng.pdf. Accessed 27 May.

40. Izumi Y, Tsuji I, Ohkubo T, Kuwahara A, Nishino Y, Hisamichi S: Impact of smoking habit on medical care use and its costs: a prospective observation of National Health Insurance beneficiaries in Japan. Int J Epidemiol 2001, 30:616-621.

41. Azagba S, Sharaf MF, Xiao Liu C: Disparities in health care utilization by smoking status in Canada. Int J Publ Health 2013. Feb 24. [Epub ahead of print].

42. Kahende JW, Adhikari B, Maurice E, Rock V, Malarcher A: Disparities in health care utilization by smoking status-NHANES 1999-2004. Int J Environ Res Pub Health 2009, 6:1095-1106.

43. Jorm LR, Shepherd LC, Rogers KD, Blyth FM: Smoking and use of primary care services: findings from a population-based cohort study linked with administrative claims data. BMC Health Serv Res 2012, 12:263.

44. Gallus S, Muttarak R, Franchi M, Pacifici R, Colombo P, Boffetta P, Leon ME, La Vecchia C: Why do smokers quit? Eur J Canc Prev 2013, 22:96-101.

45. Fidler JA, West R: Self-perceived smoking motives and their correlates in a general population sample. Nicotine Tob Res 2009, 10:1182-1188.

46. Chapman S, Wong WL, Smith W: Self-exempting beliefs about smoking and health: differences between smokers and ex-smokers. Am J Publ Health 1993, 83:215-219.

47. Weitoft GR, Eliasson M, Rosen M: Underweight, overweight and obesity as risk factors for mortality and hospitalization. Scand J Publ Health 2008, 36:169-176

48. Raebel MA, Malone DC, Conner DA, Xu S, Porter JA, Lanty FA: Health services use and health care costs of obese and nonobese individuals. Arch Intern Med 2004, 164:2135-2140.

49. Thompson D, Brown JB, Nichols GA, Elmer PJ, Oster G: Body mass index and future healthcare costs: a retrospective cohort study. Obes Res 2001, 9:210-218.

50. Andreeva T, Sturm R, Ringel JS: Moderate and severe obesity have large differences in health care costs. Obes Res 2004, 12:1936-1943.

51. Calza S, Decarli A, Ferraroni M: Obesity and prevalence of chronic diseases in the 1999-2000 Italian National Health Survey. BMC Publ Health 2008, 8:140-149.

52. Tekkel M, Veideman T, Rahu M: Use of mammography, Pap test and prostate examination by body mass index during the developmental period of cancer screening in Estonia. Publ Health 2011, 125:697-703.

53. Sims M, Maxwell R, Bauld L, Gilmore A: Short term impact of smoke-free legislation in England: retrospective analysis of hospital admissions for myocardial infarction. BMJ 2010, 340:c2161.

54. Anderson P, Chisolm D, Fuhr DC: Effectiveness and cost-effectiveness of policies and programmes to reduce the harm caused by alcohol. Lancet 2009, 373:2234-2246.

55. Kim D, Kawachi I: Food taxation and pricing strategies to "thin out" the obesity epidemic. Am J Prev Med 2006, 30:430-437.

doi:10.1186/1471-2458-13-772

Cite this article as: Vals et al:: Alcohol consumption, smoking and overweight as a burden for health care services utilization: a crosssectional study in Estonia. BMC Public Health 2013 13:772. 